\title{
Harmonized methods of melissopalynology
}

\author{
Werner Von Der OHE ${ }^{a *}$, Livia PeRsano Oddo ${ }^{\mathrm{b}}$, Maria Lucia PiAnA ${ }^{\mathrm{b}}$, \\ Monique MORLOT $^{\mathrm{c}}$, Peter MARTIN $^{\mathrm{d}}$ \\ a LAVES - Institut für Bienenkunde, Celle, Germany \\ ${ }^{\mathrm{b}}$ Istituto Sperimentale per la Zoologia Agraria, Sezione di Apicoltura, Roma, Italy \\ ${ }^{\mathrm{c}}$ Laboratory Family Michaud, Gan, France \\ d Honey International Packers Association, London, UK
}

(Received 20 February 2004; revised 3 June 2004; accepted 10 August 2004)

honey / pollen analysis / melissopalynology

\section{INTRODUCTION}

Pollen analysis of honey, or melissopalynology, is of great importance for quality control. Honey always includes numerous pollen grains (mainly from the plant species foraged by honey bees) and honeydew elements (like wax tubes, algae and fungal spores) that altogether provide a good fingerprint of the environment where the honey comes from. Pollen analysis can therefore be useful to determine and control the geographical and botanical origin of honeys even if sensory and physico-chemical analyses are also needed for a correct diagnosis of botanical origin. Moreover, pollen analysis provides some important information about honey extraction and filtration, fermentation (Russmann, 1998), some kinds of adulteration (Kerkvliet et al., 1995) and hygienic aspects such as contamination with mineral dust, soot, or starch grains (Louveaux et al., 1978).

Melissopalynology was an early branch of palynology (study of pollen and spores): the first work on the microscopy of honey dates back to the end of the XIXth century (Pfister, 1895), and the studies carried out by Zander $(1935,1937,1941,1949,1951)$ contributed to build the scientific basis of this analytical tech- nique. A method of melissopalynology was elaborated and proposed by the International Commission for Bee Botany (ICBB) and published in 1978 (Louveaux et al., 1978).

Even if this method has shortcomings and others have been proposed since to improve the accuracy of the analysis, both for the identification of pollen types and for the precision of the respective concentration values (Low et al., 1989; Lutier and Vaissière, 1993; Bryant and Jones, 2001; Jones and Bryant, 2001a, b), the ICBB method remains a well established method in most European laboratories involved in routine honey analyses and it is considered adequate for the practical purpose of verifying if the pollen spectrum complies with the declared botanical and geographical origin of a honey sample.

Since many laboratories adopted some minor changes to the original ICBB method in their routine work, the need for harmonizing, implementing and validating this method was discussed at the meetings of the International Honey Commission of Apimondia (1998, 1999). A working group was organized, in order to work out some further details on the method, reduce some of the variability arising from sample preparation and the number of grains counted, and provide, through ring trials, the precision

\footnotetext{
* Corresponding author: werner.von-der-ohe@laves.niedersachsen.de
} 
parameters of the method (repeatability and reproducibility).

A procedure with more detailed instructions to determine the spectrum of pollen types in honey in terms of relative frequencies (qualitative melissopalynological analysis) was prepared. After some further discussions, contributions and revisions, the consistency of method was tested in a ring trial performed in 1999 and the precision parameters were calculated. In 2003, a procedure was finalized to determine the absolute numbers of plant elements in honey (quantitative melissopalynological analysis), and another ring trial was performed to determine its precision parameters.

Here we present these harmonized methods for qualitative and quantitative analyses along with the results of the ring trials. The original paper (Louveaux et al., 1978) can be referred to for additional information on the microscopic analysis of honey. Based on results of melissopalynological analyses of European unifloral honeys (Persano Oddo and Piro, 2004), some elements for the interpretation of palynological results for the determination of botanical origin are also presented.

\section{METHOD OF QUALITATIVE MELISSOPALYNOLOGICAL ANALYSIS}

\subsection{Preparation of honey}

Weigh $10 \mathrm{~g}$ of honey to the nearest $0.1 \mathrm{~g}$ into a pointed glass centrifuge tube (capacity ca. $50 \mathrm{~mL}$ ). Add $20 \mathrm{~mL}$ of distilled water $\left(20-40{ }^{\circ} \mathrm{C}\right)$ and dissolve the honey. Centrifuge this solution for $10 \mathrm{~min}$ at $1000 \mathrm{~g}$. Decant the supernatant liquid. Add $20 \mathrm{~mL}$ of distilled water to completely dissolve the remaining sugar crystals and use a micro-spatula or a Pasteur pipette to get into the tip of the centrifuge tube. Disposable plastic Pasteur pipettes (volume $1 \mathrm{~mL}$ ) are recommended to avoid contamination with pollen from other honey samples. Centrifuge for $5 \mathrm{~min}$ at $1000 \mathrm{~g}$. Decant the supernatant liquid and remove all but the last drop by placing the tube up side down at a $45^{\circ}$ angle to allow the remaining excess liquid to be taken up on absorbent paper.

Heat a heating plate to $40{ }^{\circ} \mathrm{C}$ and liquefy the glycerine jelly (mounting medium; Kaiser's Glycerol Gelatine $^{\mathrm{TM}}$ Merck 1.09242.0100) by warming it to $\leq 40{ }^{\circ} \mathrm{C}$ (either on the heating plate or in a water bath). The glycerine jelly can be either clear or coloured by adding some drops of $0.1 \%(\mathrm{w} / \mathrm{v})$ basic fuchsine ethanol solution $(0.5-1 \mathrm{~mL}$ of this solution in $10 \mathrm{~mL}$ of fluid glycerine jelly). Use a waterproof marker to draw a square of $22 \times 22 \mathrm{~mm}$ on the microscope slide. Put the microscope slide onto the heating plate. If slides have to be kept for a long period, it is better to draw the square on the back of the microscopic slide or directly onto the heating plate with the permanent marker to prevent discoloration of the marking and unintentional dyeing of the pollen grains.

Mix the sediment thoroughly with a Pasteur pipette and transfer the entire sediment with this pipette on the slide. Some minor pollen loss that may occur at this stage is acceptable, since the method is for qualitative analysis. Spread the sediment evenly with a micro spatula over the marked area of $22 \times 22 \mathrm{~mm}$. For honey very rich or very poor in sediment, the surface may be too large or too small to permit an easy observation of the slide. In such cases, it is possible to spread the sediment over a more suitable surface by drawing a square bigger or smaller than $22 \times 22 \mathrm{~mm}$. Leave the slide on the heating plate only for the time strictly necessary to dry the sediment.

Warm up some cover slips $(22 \times 22 \mathrm{~mm}$ or another size as appropriate) on the heating plate. Take one drop of glycerine jelly and apply it onto the cover slip to form a large cross diagonally. By doing so, the pollen grains will remain in their drying position when lowering the cover slip over the dried sediment. Place the cover slip on the slide very slowly to avoid air bubbles. For an even dispersion of the glycerine jelly and uniform swelling of the pollen grains, leave the preparation on the heating plate for $5 \mathrm{~min}$. Never apply the drop of glycerine jelly directly onto the dried sediment.

During the whole procedure, great care must be taken to prevent any contamination from foreign pollen, coming from either previous honey preparations (disposable supplies are recommended as far as possible) or from airborne pollen grains (close windows and limit the exposure).

\subsection{Identification and counting of the plant elements in the sediment}

It is necessary to count at least 300 pollen grains for an estimation of the relative frequencies of pollen types and 500 to 1000 pollen grains for the determination of relative frequencies (Behm et al., 1996).

The examination under the microscope is carried out at the magnification that is most suitable for identifying the various elements in the sediment (400 to $1000 \times$ ). After a first general check to ascertain the main types and density of pollen grains, the relative frequencies of each pollen type are determined as follows. Identify and count pollen grains in groups of 100 , following 5 parallel equidistant lines uniformly 


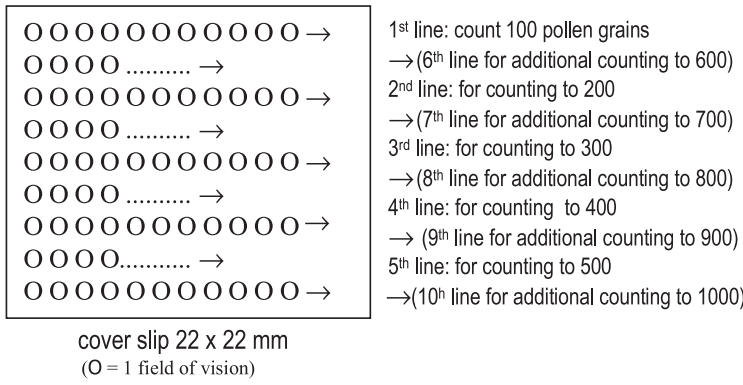

Figure 1. Matrix for counting pollen grains that guarantees a homogeneous examination of the slide $(\mathrm{O}=\mathrm{a}$ whole microscopic field of view). distributed from one edge of the cover slip to the other, until 500 grains are counted. If the relative frequencies have not stabilised or if the count of 500 pollen grains is not sufficient for interpretation (complex spectrum, over-represented pollen, abundant pollen of nectarless plants or other conditions that can mask the actual nectar source of the honey), continue the count to 1000 following another 5 parallel lines situated between the first 5 .

For analyzing the slide, the matrix presented in Figure 1 should be used to guarantee a homogeneous examination of the slide. The individual fields of vision (counting stops) should be evenly distributed along the line, and the distance between counting stops should be calculated based upon the density of the pollen grains in the preparation, and on the size of the field of vision. In case of a honey with very low pollen content, it may be necessary to count a complete sequence of successive fields of vision along the line.

Count abortive, irregular or broken pollen grains if they can be identified. Note separately non-identifiable or non-identified grains. Also note separately honeydew elements (HDE), i.e. fungal spores, hyphae and microscopic algae. Note other constituents of the sediment, like finely granulated and microcrystalline matter (Demianowicz, 1963), yeasts, impurities, soot particles, fat corpuscles, starch, plant particles.

If the sediment contains a high percentage of overrepresented pollen (such as Myosotis, Castanea or Eucalyptus), it is recommended to perform a second count excluding the over-represented pollen in order to determine more precisely the relative abundance of the other pollen types.

This procedure requires a variable amount of time depending upon the complexity of the pollen spectrum and the experience of the pollen analyst (usually $30 \mathrm{~min}$ to $1 \mathrm{~h}$ ).

\subsection{Calculation and reporting of results}

For each pollen type, calculate the relative frequency as the respective percentage with respect to the total number of pollen grains counted. Only stabilized counts based on a total of at least 500 grains should be expressed as percentages (Behm et al., 1996).

For the determination of the botanical origin of the honey, recalculate the relative frequency excluding pollen from nectarless plants. If one or several overrepresented pollen types are present and other evaluations indicate that the correspondent nectar is unimportant (quantitative pollen analysis, sensory, etc.), recalculate the relative frequency excluding also these pollen types.

Pollen types should be referred by botanical genus or species names only when they have been reliably determined at the genus or species level, respectively, which rarely occurs. Otherwise, a note should be added after the scientific name, such as group, form or type, to indicate that the term is used in a wider sense.

\subsection{Interpretation of the results}

For the identification of pollen types and the interpretation of pollen spectra, specific training and extensive experience are required. A collection of reference pollen slides and photographic atlas are very helpful (Maurizio and Louveaux, 1965; Sawyer, 1988; Ricciardelli d'Albore, 1997, 1998).

\subsubsection{Botanical origin}

The determination of the botanical origin is based on the relative frequencies of the pollen types of nectariferous species. However, the very different levels of abundance of a given pollen type in the nectar of the plant that produces it, in addition to other sources of variability, such as secondary, tertiary and quaternary enrichment, require particular caution in the interpretation of melissopalynological results. Secondary enrichment is defined as the inclusion of pollen inside the hive, while tertiary enrichment can occur during the extraction process of the honey and quaternary enrichment can come from aerial contamination.

In general, a honey is considered as coming predominantly from a given botanical origin (unifloral honey) if the relative frequency of the pollen of that 
Table I. Relative level of abundance and relative frequency of the main pollen types in various unifloral honeys (Persano Oddo et al., 1995; Persano Oddo and Piro, 2004).

\begin{tabular}{llll}
\hline Under-represented pollen & $\begin{array}{l}\text { Pollen which can be under- Normally represented } \\
\text { represented in some cases }\end{array}$ & pollen \\
\hline Arbutus $(8-20 \%)$ & Calluna $(10-77 \%)$ & Erica $(>45 \%)$ & Castanea $(>86 \%)$ \\
Carduus $(5-25 \%)$ & Helianthus $(12-92 \%)$ & Eryobotrya $(>45 \%)$ & Eucalyptus $(>83 \%)$ \\
Citrus $(2-42 \%)$ & Rhododendron $(15-77 \%)$ & Hedysarum $(>50 \%)$ & Brassica napus $(>60 \%)$ \\
Lavandula latifolia $(15-42 \%)$ & Robinia $(7-60 \%)$ & & Phacelia $(>60 \%)$ \\
Lavandula $\times$ intermedia $(1-20 \%)$ & Rosmarinus $(10-57 \%)$ & & \\
Medicago $(1-10 \%)$ & Thymus $(13-68 \%)$ & & \\
Taraxacum $(5-40 \%)$ & Tilia $(1-56 \%)$ & & \\
\end{tabular}

taxon exceeds $45 \%$. It is considered to be predominately honeydew if the ratio of the number of honeydew elements (HDE) to that of pollen grains (PG) exceeds 3 . However, because of the numerous overor under-represented pollen types, the pollen percentages and the HDE/PG ratios can vary greatly between different unifloral honeys (Tab. I). Therefore, for a correct interpretation of botanical origin, it is recommended that other characteristics of the honey be taken into account such as sensory and physicochemical data and in some cases also the absolute number of plant elements (obtained from quantitative analysis).

\subsubsection{Geographical origin}

The determination of geographical origin is based on the entire pollen spectrum being consistent with the flora of a particular region and with any reference spectra or descriptions in the literature (Zander, 1935, 1937, 1941, 1949, 1951; Louveaux et al., 1978). Recently, some computer aided methods for the identification of geographical origin have been developed (Battesti and Goeury, 1992).

\section{METHOD OF QUANTITATIVE MELISSOPALYNOLOGICAL ANALYSIS}

\subsection{Preparation of honey}

Weigh $10 \mathrm{~g}$ of honey, noting the weight to the first decimal place, into a beaker and mix with about $40 \mathrm{~mL}$ of tepid distilled water (20$40{ }^{\circ} \mathrm{C}$ ). The volume of water is greater than for the qualitative analysis because a thorough dilution of the honey sample ensures an easier passage through the filtering membrane and a better distribution of the pollen grains on the filter surface. In order to ease pollen recognition, a few drops of $0.1 \%$ ethanol solution of basic fuchsine may be added directly to the water. Assemble a vacuum filtration apparatus, using a membrane filter of mixed cellulose esters, with a pore size of $3 \mu \mathrm{m}$ and diameter 25$47 \mathrm{~mm}$ (glass micro-analysis filter holders and membrane filters such as SSWP02500 or SSWP 04700 from Millipore - http://www.millipore.com - meet these requirements). Pour in a little water to soak the filter and then pour in the honey solution. Rinse the beaker a few times with a small quantity of distilled water and add it to the vacuum filtration apparatus. Carefully rinse the walls of the filter holder. Remove the filter by means of tweezers with flat ends and place it to dry on a heating plate maintained at about $40{ }^{\circ} \mathrm{C}$. Prepare a slide with some drops of immersion oil, place the filter on the slide, add one or two more drops of immersion oil on the surface of the filter and cover with a cover slip of appropriate size. The oil will make the filter transparent. If a $47 \mathrm{~mm}$ filter is used, cut it into two parts and prepare 2 separate slides with each of the 2 parts.

\subsection{Counting of plant elements}

Use the most appropriate microscope magnification to look at the slide (for optimal counting, the number of elements in each field should be between 10 and 20). It is necessary to count at least 500 elements (PG and HDE) in at least 100 fields. 
In order to examine uniformly the entire surface, look at fields in 10 equidistant parallel lines from one edge of the filter to the other. While moving from one field to the next, it is advisable not to look into the microscope to avoid any unconscious choice of the field. Count all PG and HDE separately. If the slide has only a few plant elements, it may be necessary to count 10 more lines in order to obtain a total count of 500 plant elements. If the slide is excessively rich in plant elements, it may be necessary to carry out another preparation with a smaller quantity of honey.

\subsection{Calculation, expression and interpretation of results}

To calculate the absolute number of plant elements $(N)$, it is necessary to calculate the surface area of the part of the filter containing sediment $(S)$ and the area of the microscope fields at the magnification used $(s)$. The latter can be measured using a stage micrometer.

The absolute number of pollen grains in $10 \mathrm{~g}$ of honey (PG/10 g) and the absolute number of honeydew elements in $10 \mathrm{~g}$ of honey (HDE/10 $\mathrm{g}$ ) are calculated as follows:

$$
\begin{gathered}
P G / 10 g=\frac{S \times n_{P G} \times 10}{s \times a \times p} \\
H D E / 10 g=\frac{S \times n_{H D E} \times 10}{s \times a \times p}
\end{gathered}
$$

where:

$S$ is the surface area of the part of the filter containing sediment $\left(\mathrm{mm}^{2}\right)$

$s$ is the area of one microscopic field at the magnification used $\left(\mathrm{mm}^{2}\right)$

$n_{P G}$ is the total number of pollen grains (PG) counted

$n_{H D E}$ is the total number of honeydew elements (HDE) counted

$a$ is the number of fields counted

$p$ is the weight of honey $(\mathrm{g})$.

The total number of plant constituents $(N)$ in 10 grams of honey is the sum of the results calculated by formulae $I$ and $I I$. The results are expressed in thousands $\left(10^{3}\right)$, rounding to the nearest thousand (e.g. $N / 10 \mathrm{~g}=26342$ is expressed as $\left.26 \times 10^{3}\right)$.
According to the total number of plant elements, honeys are placed into one of the following 5 classes:

- Class I: $N \leq 20 \times 10^{3}$, includes unifloral honeys with under-represented pollen.

- Class II: $21 \times 10^{3} \leq N \leq 100 \times 10^{3}$, includes most of multifloral honeys, honeydew honeys and mixtures of flower and honeydew honeys.

- Class III: $101 \times 10^{3} \leq N \leq 500 \times 10^{3}$, includes unifloral honeys with over-represented pollen and honeydew honeys.

- Class IV: $501 \times 10^{3} \leq N \leq 10^{6}$, includes unifloral honeys with strongly over-represented pollen and some pressed honeys.

- Class $V: N>10^{6}$, includes almost only pressed honey.

\section{DETERMINATION OF THE PRECISION PARAMETERS}

\subsection{Method for qualitative analysis}

The ring trials on the qualitative method of melissopalynology were carried out by the International Honey Commission of Apimondia conducted by Institut f. Bienenkunde Celle to verify the level of consistency through the evaluation of repeatability and reproducibility of the harmonized method. Seventeen experienced pollen analysts in 15 laboratories and 8 countries participated in the ring trial (see list in the Acknowledgements). One sample of homogenous floral honey (spring honey with a relative high amount of Brassica napus pollen) was sent to each participant. Five preparations were made, and 1000 pollen grains were identified in each preparation, recording the results at 300,500 and 1000 grains. The results of statistical analyses related to 500 and 1000 counted pollen grains are reported in Table II. Especially mean, standard deviation, outliers, repeatability ( $r$ ), reproducibility $(\mathrm{R})$, and the Relative Standard Deviation of $\mathrm{r}$ and $\mathrm{R}\left(\mathrm{RSD}_{\mathrm{r}} \%\right.$ and $\mathrm{RSD}_{\mathrm{R}} \%$ ) were calculated (ISO 5725-2, 1994; Kromidas, 1999). In the field of validation of methods there are the statistical terms repeatability " $r$ " and reproducibility " $R$ ". Repeatability describes the absolute difference between two results produced by one person with identical sample and same equipments within the shortest possible time. Reproducibility describes 
Table II. Results of the ring trial on qualitative melissopalynological method performed by 17 experienced pollen analysts in 15 laboratories $\left(\mathrm{RSD}_{\mathrm{r}} \%=\right.$ Relative Deviation Standard of $\mathrm{r} ; \mathrm{RSD}_{\mathrm{R}} \%=$ Relative Standard Deviation of R).

\begin{tabular}{|c|c|c|c|c|c|c|c|c|}
\hline Pollen type & $\begin{array}{l}\text { Pollen grains } \\
\text { counted }\end{array}$ & $\begin{array}{l}\text { Average number } \\
\text { of grains of the } \\
\text { type }\end{array}$ & $\begin{array}{c}\text { Average relative } \\
\text { frequency of grains } \\
\text { of the type }(\%)\end{array}$ & $\begin{array}{l}\text { Standard } \\
\text { deviation } \\
\text { of } \mathrm{R}\end{array}$ & $\begin{array}{l}\text { Repeata- } \\
\text { bility } \\
\text { (r) }\end{array}$ & $\begin{array}{l}\text { Reprodu- } \\
\text { cibility } \\
\text { (R) }\end{array}$ & $\mathrm{RSD}_{\mathrm{r}} \%$ & $\mathrm{RSD}_{\mathrm{R}} \%$ \\
\hline \multirow[t]{2}{*}{ Brassicaceae } & 500 & 370.2 & 74.1 & 2.7 & 6.5 & 7.5 & 3.1 & 3.6 \\
\hline & 1000 & 742.7 & 74.3 & 2.4 & 5.6 & 6.9 & 2.7 & 3.3 \\
\hline \multirow[t]{2}{*}{ Rosaceae } & 500 & 52.8 & 10.6 & 2.8 & 4.8 & 7.9 & 16.0 & 26.3 \\
\hline & 1000 & 113.6 & 11.4 & 1.8 & 3.4 & 5.2 & 10.5 & 16.1 \\
\hline \multirow[t]{2}{*}{ Acer } & 500 & 6.8 & 1.4 & 0.7 & 1.0 & 2.1 & 25.3 & 53.0 \\
\hline & 1000 & 14.2 & 1.4 & 0.7 & 1.0 & 1.8 & 25.3 & 45.5 \\
\hline \multirow[t]{2}{*}{ Aesculus } & 500 & 10.6 & 2.1 & 0.8 & 1.6 & 2.2 & 26.9 & 37.0 \\
\hline & 1000 & 21.9 & 2.2 & 0.5 & 1.0 & 1.4 & 16.1 & 22.5 \\
\hline Nectarless & 500 & 36.1 & 7.2 & 1.6 & 4.2 & 4.6 & 20.6 & 22.6 \\
\hline taxa & 1000 & 68.6 & 7.0 & 1.4 & 2.7 & 3.8 & 13.6 & 19.2 \\
\hline
\end{tabular}

the absolute difference between two results produced by two laboratories with identical samples. In both cases the significance is $95 \%$. The parameters $\mathrm{RSD}_{\mathrm{r}}$ and $\mathrm{RSD}_{\mathrm{R}}$ are valuable for determining the precision of analytical methods, and can be calculated from $\mathrm{r}$ and $\mathrm{R}$ values according to the formulae:

$$
\begin{aligned}
\operatorname{RSD}_{\mathrm{r}} \% & =\frac{r}{2.83 \bar{x}} \times 100 \\
\mathrm{RSD}_{\mathrm{R}} \% & =\frac{R}{2.83 \bar{x}} \times 100
\end{aligned}
$$

The relationship between the proportion of a given pollen type and the precision parameters for this proportion $\left(\mathrm{r}, \mathrm{R}, \mathrm{RSD}_{\mathrm{r}} \%\right.$ and $\mathrm{RSD}_{\mathrm{R}} \%$ ) followed a logarithmic slope (Fig. 2). Precision is very poor at low frequencies, while higher relative frequencies result in better repeatability and reproducibility.

Precision increases if 1000 pollen grains are counted instead of 500. However, for high frequencies, the difference is small and the precision is satisfactory even at the lower count of 500 grains, while, on the other hand, for low pollen frequencies the precision increases, but remains unsatisfactory.

Differences between " $r$ "- and "R"-values are relatively small. Probably the human component is less important than usually considered, and the scattering of pollen grains from preparation to preparation is not much lower within a laboratory than between laboratories.
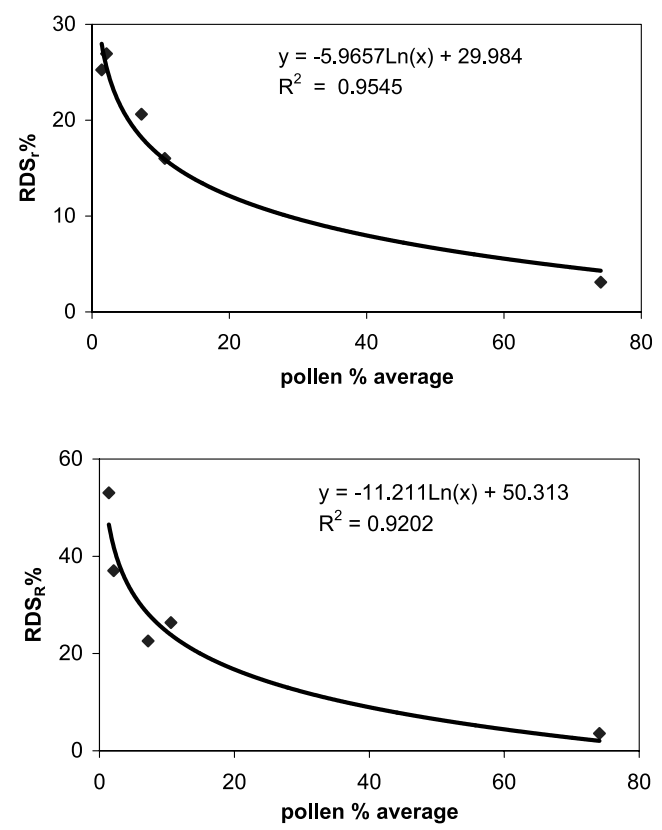

Figure 2. Relationship between the Relative Standard Deviation of ' $\mathrm{r}$ ' and 'R' ( $\mathrm{RSD}_{\mathrm{r}} \%$ and $\mathrm{RSD}_{\mathrm{R}} \%$ ) and the average pollen frequency based on the data of Table II (500 grains counted).

The results of the ring trial are in a very good agreement with those of other trials carried out by the German Honey-Analytical-Workshop and the German Institute of Standardisation, which included different pollen proportion values (DIN 
Table III. Indicative values of the Relative Standard Deviation of $\mathrm{r}$ and $\mathrm{R}\left(\mathrm{RSD}_{\mathrm{r}} \%\right.$ and $\left.\mathrm{RSD}_{\mathrm{R}} \%\right)$ in relation to some relative frequencies of pollen occurrence when counting 500 or 1000 grains.

\begin{tabular}{lcccc}
\hline $\begin{array}{l}\text { Relative pollen } \\
\text { frequency (\%) }\end{array}$ & \multicolumn{2}{c}{$\begin{array}{c}500 \text { grains } \\
\text { counted }\end{array}$} & \multicolumn{2}{c}{$\begin{array}{c}1000 \text { grains } \\
\text { counted }\end{array}$} \\
\cline { 2 - 5 } & $\mathrm{RSD}_{\mathrm{r}} \%$ & $\mathrm{RSD}_{\mathrm{R}} \%$ & $\mathrm{RSD}_{\mathrm{r}} \%$ & $\mathrm{RSD}_{\mathrm{R}} \%$ \\
\hline 5 & 25 & 35 & 20 & 30 \\
10 & 20 & 25 & 15 & 20 \\
20 & 15 & 20 & 10 & 15 \\
30 & 10 & 15 & $<5$ & $<10$ \\
50 & $<5$ & $<10$ & $<5$ & $<5$ \\
\hline
\end{tabular}

10760, 2002). From IHC and German results it was possible to indicate some reference values of $\mathrm{RSD}_{\mathrm{r}} \%$ and $\mathrm{RSD}_{\mathrm{R}} \%$, in relation to pollen frequency values (Tab. III).

\subsection{Method for quantitative analysis}

The interlaboratory study was conducted by the Istituto Sperimentale per la Zoologia Agraria (Italy) and 16 experienced pollen analysts from 12 laboratories participated in the ring trial (see list at the Acknowledgements). Three samples of homogenous floral honeys were sent to the participants. The three samples had different absolute pollen number: low (honey mainly from Robinia pseudacacia), medium (multifloral spring honey with a relative high amount of Brassicaceae pollen) and high (summer honey mainly from Eucalyptus sp.) Each participant made 2 preparations from each honey sample, following the method for quantitative analysis described above, and each preparation was counted up to at least 100 fields of view under the microscope and at least 500 plant elements.

For quantitative pollen analysis, the precision parameters also improved when average values were higher. Repeatability values were quite good for all 3 pollen concentrations $\left(\mathrm{RSD}_{\mathrm{r}} \%\right.$ between 7 and 16\%; Tab. IV); reproducibility values were higher $\left(\mathrm{RSD}_{\mathrm{r}} \%>30 \%\right.$ for level 2$)$, but differences between " $R$ " and " $r$ " values were in the norm $(\mathrm{R} / \mathrm{r}$ ratio between 2 and 3$)$.

\section{DISCUSSION AND CONCLUSIONS}

All the physicochemical data used for the unifloral honeys descriptions (Persano Oddo and Piro, 2004) were obtained through harmonized and validated methods of analysis (Bogdanov et al., 1997) and also for the pollen analyses an harmonized and validated procedure was established on the basis of the classical method of International Commission for Bee Botany (Louveaux et al., 1978), optimising the method and fulfilling the necessary work of ring trials.

The described procedures for the qualitative and quantitative melissopalynological analysis represent a further effort of IHC for implementing, harmonizing and validating the analytical methods concerning honey. Such harmonized methods are necessary for quality assurance and to insure that results of the various laboratories performing honey analysis are comparable.

Even if more recently developed methods (Lutier and Vaissière, 1993; Jones and Bryant, 2001a, b) can produce better results and may therefore be useful for research applications, the ICBB method is widely used in European laboratories and it is the one which was used to produce the data for the unifloral honeys descriptions (Persano Oddo and Piro, 2004).

Pollen analysis is an indispensable method to authenticate honey origin and characteristics. It is very effective to determine and control the geographical origin of honeys and it also provides information about other important quality aspects. It also contributes, together with sensory and physicochemical analyses, to

Table IV. Results of the ring trial on quantitative melissopalynological method performed by 16 experienced pollen analysts from 12 laboratories $\left(\mathrm{RSD}_{\mathrm{r}} \%=\right.$ Relative Standard Deviation of $\mathrm{r} ; \mathrm{RSD}_{\mathrm{R}} \%=$ Relative Standard Deviation of R).

\begin{tabular}{lccccccc}
\hline Sample & $\begin{array}{c}\text { Average } \\
\left(N / 10 \mathrm{~g} \times 10^{3}\right)\end{array}$ & $\begin{array}{c}\text { Standard } \\
\text { deviation of } \mathrm{r}\end{array}$ & $\begin{array}{c}\text { Standard deviation } \\
\text { of } \mathrm{R}\end{array}$ & $\begin{array}{c}\text { Repeatability } \\
(\mathrm{r})\end{array}$ & $\begin{array}{c}\text { Reproducibility } \\
(\mathrm{R})\end{array}$ & $\mathrm{RSD}_{\mathrm{r}} \%$ & $\mathrm{RSD}_{\mathrm{R}} \%$ \\
\hline Low & 9.5 & 1.1 & 2.8 & 3.2 & 8.0 & 12.0 & 29.8 \\
Medium & 24.6 & 3.9 & 8.0 & 10.9 & 22.5 & 15.7 & 32.4 \\
High & 143.8 & 9.5 & 27.7 & 27.0 & 78.3 & 6.6 & 19.3 \\
\hline
\end{tabular}


the determination and control of the botanical origin of honeys. For these purposes, it is not necessary to determine all existing pollen types in the honey and, on the other hand, the natural variability of honey itself makes it difficult to define extremely precise references or limits for the pollen spectrum of a given honey type. Indeed, the main critical point of melissopalynological analysis remains the correctness of pollen identification and the subsequent interpretation of the results. These require from the analyst a considerable experience in melissopalynology and a good general knowledge of this amazing product that is honey.

\section{ACKNOWLEDGEMENTS}

We like to thank all participants in the ring trials for their good cooperation: A. Baggio (Italy), G. Beckh (Germany), P. Belligoli (Italy), D. Bubalo (Croatia) K. Bieri (Switzerland), M. Capelli (Italy), C. Costantini (Italy), E. Faggionato (Italy), P. Ferrazzi (Italy), E. Gouta (Greece), F. Grillenzoni (Italy), H. Horn (Germany), J. Kerkvliet (Netherlands), J. Lheritier (France), M. Morlot (France), H. Pechhacker (Austria), L. Persano Oddo (Italy), L. Piana (Italy), S. Piperno (Italy), J. Probst (USA), S. Prosperi (Italy), K. Ruoff (Finland), H. Rußmann (Germany), A. Sabatini (Italy), A. Savino (Italy), G. Sesta (Italy), M. Stefano (Italy), D. Störmer (Germany), K. von der Ohe (Germany).

\section{REFERENCES}

Battesti M.J., Goeury C. (1992) Efficacité de l'analyse melissopalynologie quantitative pour la certification des origines géographiques et botaniques des miels : le modèle des miels corses, Rev. Paleobot. Palynol. 75, 77-102.

Behm F., von der Ohe K., Henrich W. (1996) Zuverlässigkeit der Pollenanalyse von Honig. Bestimmung der Pollenhäufigkeit, Dtsch. Lebensm. 92, 183-187.

Bogdanov S., Martin P., Lüllmann C. (1997) Harmonized methods of the European Honey Commission, Apidologie extra issue, 1-59.

Bryant V.M., Jones G.D. (2001) The R-Values of honey: pollen coefficients, Palynology 25, 11-28.

Demianowicz Z. (1963) Sur l'origine des macles d'oxalate de calcium contenues dans les miels de tilleul, Ann. Abeille 6, 249-255.

DIN (Deutsches Institut für Normung) (2002) Untersuchung von Honig - Bestimmung der relativen Pollenhäufigkeit, DIN 10760: 2002-05, Berlin (http://www.din.de, http://www.beuth.de).

International Honey Commission (IHC). Minutes of the IHC meetings: Toledo (1998), Dijon (1999), http://www.apis.admin.ch/host/honey/minutes.htm.
ISO 5725-2 (1994) Accuracy (trueness and precision) of measurement methods and results. Part 2: basic method for the determination of repeatability and reproducibility of a standard measurement method, Geneva (http://www.iso.org).

Jones G., Bryant V. (2001a) Is one drop enough? Proc. 9th Int. Palynol. Cong., 1996, Houston, Texas, USA Am. Assoc. Stratigraphic Palynol. Found., pp. 453-458.

Jones G., Bryant V. (2001b) Alcohol dilution of honey, Proc. 9th Int. Palynol. Congr., 1996, Houston, Texas, USA Am. Assoc. Stratigraphic Palynol. Found., pp. 483-488.

Kerkvliet J.D., Shrestha M., Tuladhar K., Manandhar H. (1995) Microscopic detection of adulteration of honey with cane sugar and cane sugar products, Apidologie 26, 131-139.

Kromidas S. (1999) Validierung in der Analytik, Wiley-VCH, Weinheim.

Low N., Schweger C., Sporns P. (1989) Precautions in the use of melissopalynology, J. Apic. Res. 28, 50-54.

Louveaux J., Maurizio A., Vorwohl G. (1978) Methods of Melissopalynology, Bee World 59, 139157.

Lutier P.M., Vaissière B.E. (1993) An improved method for pollen analysis of honey, Rev. Paleobot. Palynol. 78, 129-144.

Maurizio A., Louveaux J. (1965) Pollens de plantes mellifères d'Europe, Union des groupements apicoles français, Paris.

Persano Oddo L., Piazza M.G., Sabatini A.G., Accorti M. (1995) Characterization of unifloral honeys, Apidologie 26, 453-465.

Persano Oddo L., Piro R. (2004) Main European unifloral honeys: descriptive sheets, Apidologie 35 (Suppl. 1), S38-S81.

Pfister R. (1895) Versuch. Einer Mikroskopie des Honigs, Forschungsbereich Lebensmittel, Bez. Hyg. Pharm. 2, 25; 20.

Ricciardelli d'Albore G. (1997) Textbook of melissopalynology, Apimondia, Bucharest.

Ricciardelli d'Albore G. (1998) Mediterranean melissopalynology, Istituto di Entomologia Agraria, Università degli Studi, Perugia.

Russmann H. (1998) Hefen und Glycerin in Blütenhonigen - Nachweis einer Gärung oder einer abgestoppten Gärung, Lebensmittelchemie 52, 116-117.

Sawyer R. (1988) Honey identification, Cardiff Academic Press, UK.

Zander E. (1935, 1937, 1941, 1949, 1951) Beitrage zur Herkunftsbestimmung bei Honig. Pollengestaltung und Herkunftsbestimmung bei Blütenhonig, Bd. I Berlin, Verlag der Reichsfachgruppe Imker. Bd. II Leipzig, Liedloff, Loth u. Michaelis. Bd. III Leipzig, Liedloff, Loth u. Michaelis. Bd. IV München, Ehrenwirth. Bd. V Leipzig, Liedloff, Loth u. Michaelis. 